\title{
TEM FUTURO A CIÊNCIA DA MOTRICIDADE HUMANA?
}

\section{DOES THE SCIENCE OF HUMAN MOTRICITY HAVE A FUTURE?}

\author{
Manuel Sérgio*
}

1.A ciência da motricidade humana nasce, num mundo social e político, cartesiano e capitalista, como problema ontológico, como problema epistemológico, como problema político. Como problema ontológico, pela ausência, na Educação Física, de um paradigma organizador que norteasse o estudo e a pesquisa e em tempo, portanto, de crise e de necessária revolução científica. A Educação Física deveria apresentar-se como o ramo pedagógico de uma qualquer ciência. Mas...que ciência? E uma ciência formal, empírico-formal, ou hermenêutico-humana? Neste assunto se tocou, em breves e lúcidas palavras de Cagigal, Sergio Toro Arévalo, Eugenia Trigo, Le Boulch, Parlebas, João Batista Freire, Manoel Tubino, João Paulo Medina, Luiz Gonçalves Junior, Anna Feitosa e poucos mais. Permitam-me que intercale esta nótula, no meu discurso: se a morte o não levasse, Cagigal estaria, hoje, ao nosso lado. A sua atitude eminentemente crítica e a sua inteligência aguda não o deixariam com uma linguagem que não é reflexo da realidade. Saudemos, no entanto, o surgimento, em Espanha, de um pensador, como José Luís Pastor Pradillo, que à motricidade humana vem dedicando páginas de muito bom nível intelectual (veja-se um dos seus últimos livros, Motricidad, ámbitos e técnicas de intervención, editado pela Universidad de Alcalá, 2007). De facto, o que conhecemos conhecemo-lo pela mediação da linguagem. Como Heidegger o assinala, na Carta sobre o Humanismo (Guimarães Editores, Lisboa, p.50), "há um pertencer originário da palavra ao ser". $\mathrm{O}$ ser pensa-se, dizendo. Por isso, me parece lícito perguntar-se, se é possível, na área do conhecimento que estudamos, um vocabulário científico com a palavra físico, no lugar de pessoa. As expressões cultura física, actividade física e educação física resultam de uma linguagem que o racionalismo popularizou e universalizou e o senso comum dos políticos decretou e oficializou. Nunca será demais repetir que a Educação
Física nasce na Europa, no século XVIII e precisou do capitalismo colonizador para globalizar-se. Em 1569, em Veneza, ainda Hieronymus Mercurialis publicava o De Arte Gymnastica, obra em seis volumes, onde se distingue três tipos de ginástica: médica, militar e atlética. De referir, no entanto, que a repercussão deste livro foi tal que, além das numerosas reedições, era frequentemente citada, no século XIX, nos textos de Gutsmuths, Anton Vieth e Friedrich Jahn. No Brasil, segundo Inezil Pena Marinho, na sua História da Educação Física no Brasil, "em 1828, aparece em Pernambuco o primeiro livro editado no Brasil, sobre Educação Física e essa glória cabe a Joaquim Jerônimo Serpa. É um Tratado de Educação Física - Moral dos Meninos"(p. 33). A ciência da motricidade humana $(\mathrm{CMH})$ é inseparável da linguagem e do tempo: da linguagem típica do método fenomenológico, iniciado por Husserl e desenvolvido por MerleauPonty e da revolução hermenêutica de Heidegger e Gadamer e proveniente de um tempo em que todo o real é complexo e, por isso, em que se procura um pensamento "que compreenda que o conhecimento das partes depende do conhecimento do todo e em que o conhecimento do todo depende do conhecimento das partes"(Edgar Morin, Reformar o Pensamento, Instituto Piaget, Lisboa, p.94). E, sobre o mais, em que o "pensamento único" do Ter e do Poder se encontram em declarada agonia. A CMH torna-se ontologia porque é, também, através dela que o ser humano, no acto da transcendência, é verdadeiramente. O racionalismo assumiu-se como razão forte. A razão hermenêutica e pós-moderna afirma-se como pensamento débil, porque tudo é temporal, conjectural e histórico. A CMH, destituída de qualquer presunção metafísica, encontra na transcendência, ou superação ("o que é não pode ser" disse-o Ernst Bloch) o sentido da vida humana. De facto, a transcendência, em movimento intencional e em equipa, funciona como potenciadora de uma

"Filósofo e Professor catedrático aposentado da F.M.H. 
dimensão sapiencial, tanto no desporto, como no lazer, na saúde, na educação, no trabalho. Porque só quem quer ser-mais vive verdadeiramente. Sem esquecer-se que ser é relacionar-se. Eu sou sempre um de nós...

2. ACMH, como resistência aos métodos consagrados, às formas estabelecidas e rotineiras aceita inteiramente o conceito de complexidade. Um conceito remete ao outro. A ciência moderna, concebida como teoria para o domínio da razão sobre o mundo material, concebido como extensão e movimento, natureza passiva à disposição do ser humano, acentuou a rotura entre a natureza e a cultura, entre o corpo e o espírito, entre o natural e o artificial, entre o observador e o observado, entre o subjectivo e o objectivo. Ao invés, a CMH é contemporânea da perspectiva foucaultiana do corpo historicamente dependente; da perspectiva construtivista de Elias, a qual realça a ligação entre os factores biológicos e os sociais; da dicotomia entre corpo-objecto e corpo-vivido, que Merleau-Ponty esclarece e distingue; do corpo na abordagem psicanalítica (de Freud a Lacan); e enfim de todos aqueles que entraram de questionar "a perspectiva tradicional sobre a natureza da racionalidade"(António Damásio, O Erro de Descartes, Europa-América, Lisboa, p.13). É precisamente contra a perspectiva tradicional que Damásio defende a tese seguinte: "a emoção é uma componente integral da maquinaria da razão"(p.14). E mais adiante: "Não me parece sensato excluir as emoções e os sentimentos de qualquer concepção geral da mente"(p.172). E ainda: "enquanto os acontecimentos mentais são o resultado da actividade dos neurónios, no cérebro, a história prévia e imprescindível que os neurónios do cérebro têm de contar é a do esquema e do funcionamento do corpo"(p.236). Por seu turno, B. S. Turner refere que é, hoje, lícito substuir o "penso logo existo" pelo "consumo logo existo" (cfr. Regulating Bodies - Essays in Medical Sociology, Routledge, London, 1992). Daí, que a origem não seja o logos, mas a publicidade, o exterior, o epidérmico, o superficial. "É de facto a superfície do corpo o que se vê, que está patente, em todas as campanhas de publicidade, tornando-se o corpo, por um lado objecto de idealização, mas por outro potencial alvo de estigmatização, caso não corresponda aos padrões expressos na própria publicidade" (Maria João Cunha, A Imagem Corporal, Autonomia 27, Azeitão, 2004, p. 83). O normal é sempre o normalizado, por efeito da publicidade. E o que mais se publicita? A saúde, evidentemente! E através de que meios? Os mais espectaculares e centrados na ciência/ideologia bio-médica: a dieta e o exercício chamado físico, como se a saúde fosse possível com o físico como significante exclusivo. Em todas as definições de saúde está presente a multidisciplinaridade, pois que ser saudável pressupõe também uma "saúde social", decorrente de uma educação em direitos humanos. A CMH irroga-se o direito de pretender construir um diálogo entre todos os "homens de boa vontade" - diálogo que seja mais do que um método, porque, nele, quem ensina aprende e quem aprende ensina, de modo que todos sejamos aprendizes, através da motricidade, da vida, dos afectos, da luta por um mundo melhor. O corpo não é natureza tão-só, trata-se de uma instituição política. O corpo em acto, ou a motricidade humana, pensa-se e pratica-se como construção de sujeitos históricos, onde o possível é bem mais do que o real. A CMH é um problema epistemológico porque, através de uma inequívoca mudança de paradigma, cria um discurso novo; é um problema ontológico, pois concede prioridade à pessoa no acto da transcendência, e não só ao físico ou ao corpo-objecto, tanto ao nível da educação, como no desporto, como na saúde (onde o fitness parece descambar em erros lamentáveis, como o fisioterapeuta Luís Coelho o refere, no jonal Público, de 23 de Agosto de 2007); e é um problema político porque, nesta ciência, se tem em conta a incorporação do poder, como algo determinante na constituição de práticas estruturalmente situadas (sigo aqui o Anthony Giddens de Dualidade da Estrutura - agência e estrutura, Celta Editora, Oeiras, 2000).

3. "Na introdução do livro Epistemologia, Mario Bunge escrevia, no começo da década de oitenta do século XX, que a epistemologia, ou filosofia da ciência, se tinha tornado no domínio mais importante da filosofia, nos últimos cinquenta anos(...). A ligação às ciências, no entanto, tem constituído sempre um veículo de revigoramento da própria filosofia, desde que Platão se empenhou em estabelecer a via em que o conhecimento científico se libertava das incertezas transportadas pelas informações sensíveis, para dar lugar ao conhecimento verdadeiro" (José Luís Brandão da Luz, Introdução à Epistemologia, Imprensa NacionalCasa da Moeda, Lisboa, 2002, pp. 25/26). A "matematização galilaica da natureza" (título do parágrafo nono do livro A Crise das Ciências Europeias e a Filosofia Transcendental, em que Husserl refere os 
ganhos e perdas da idealização matemática da nature$\mathrm{za}$ ), ou a mathesis universalis, que Leibniz forcejou por desenvolver, como sustentáculo da construção do sistema das ciências - ganharam em coerência operativa o que perderam em realidade, pois que as coisas e os homens não são matemática tão-só. A ordem da lógica não integra sempre a ordem real da existência. No caso específico da $\mathrm{CMH}$, que estuda o corpo em ato, é no campo das ciências hermenêuticas, ou humanas, que é possível (e lógico) enquadrá-la. Assinalo, neste passo, que distingo três grandes categorias de ciências, na esteira de Jean Ladrière: as formais, as empírico-formais, ou da natureza, e as hermenêuticas, ou humanas. Uma epistemologia da Educação Física, ou seja, a organização do conhecimento da impropriamente denominada Educação Física, não pode esquecer que esta não é uma área de físicos, mas de pessoas no movimento intencional da transcendência (ou superação). Aqui, o físico está integral, mas superado. Portanto, as expressões "Ciência da Actividade Física" e "Ciência da Educação Física" pecam por defeito. O mesmo acontece com as "Ciências do Desporto", já que o "corpo em acto" não se circunscreve à prática desportiva. Constitui um desafio permanente para a epistemologia a clarificação progressiva do sentido da acção humana e, para tanto, a linguagem não pode ser arbitrária, mas portadora de rigor e de fundamentação. A "Cinesiologia" quase sempre foi percepcionada como uma disciplina de uma graduação (ou licenciatura) e poucas vezes se constituiu como ramo autónomo do saber. Demais, não nos limitamos à área do "movimento", mas do "movimento intencional", ou seja, da "motricidade", de acordo com a definição da escola fenomenológica. Parece-nos, indubitavelmente, ser a Motricidade Humana o nosso objecto de estudo e o espaço em que se concretiza uma prática profissional. O Desporto, a Dança, a Ergonomia, a Reabilitação, a Motricidade Infantil e enfim os vários aspectos da motricidade, do jogo ao trabalho, passando pelo Desporto, pela Saúde, o Lazer e a Educação, são as especialidades que despontam da CMH. Será preciso acrescentar que nos situamos, aqui, em pleno campo das ciências humanas? O Desporto (um exemplo, entre outros e como macro-conceito) só à luz das ciências humanas é possível estudá-lo. Ele beneficia também da aplicação de formulações matemáticas (como a economia, a psicologia, a sociologia, etc.), mas seria redutor fazer da matemática o seu radical fundante. Os cursos universitários de Desporto, após larga e porfiada reflexão, deverão questionar os seus habituais "curricula" e aproximarem-se, sem equívocos, do corpo, dentro de três grandes níveis: o físico-biológico, o sócio-político e o cultural e noético. Não defendo uma ideologia instigadora de uma cultura única, mas a superação de uma teorização que só se ocupa dos elementos determinados e não mostra saber, nem vontade, para se adentrar na complexidade determinante. As mensagens que muitos professores dos cursos universitários de desporto transmitem aos alunos não passam de metalinguagem, por ausência de capacidade de produzir novas mensagens. Não estará em crise a ideia de corpo-sujeito, quando o corpo é objecto de desejo; quando o piercing e outras técnicas de alteração corporal fazem do meu corpo o meu objecto preferido; quando o culto da performance, tanto hipervaloriza como subvaloriza um corpo que é objecto tão-só? E a fadiga de ser si mesmo, na expressão de A. Ehrenberg (cfr. La fatigue d'être soi. Dépression et société, Odile Jacob, Paris, 1998) não pode hostilizar a pessoa, em relação ao seu próprio corpo? Qual a diferença entre a alta competição e o circo? Na body-art, o corpo não é instrumento também?...

4. Mesmo que se conserve a expressão "Educação Física”, ou "Educação Física e Desporto", por interesses vários, que não discuto, neste passo, julgo que será de manter a "Motricidade Humana", como o objecto de estudo desta área. Conhecimento, ação, vontade, afectividade interpenetram-se e realizam-se de tal modo, na motricidade humana, que é ilusório, para os "professores de Educação Física", admitir problemas puramente físicos, na sua profissão. O que se proclamou, no passado, após Descartes, como verdade, merece questionamento, atualmente. Kant definiu, de modo exemplar, no seu pequeno tratado sobre educação, o que o senso comum entendia por Ginástica: "é a educação daquilo que é natureza, no homem". Ele não conhecia a existência de sistemas autopoiéticos. Se do século XVIII até hoje, nada tivesse florescido de original, de inovador, então deixaria de ser uma realidade indesmentível o processo histórico. Uma teoria sobre o ser humano não pode senão assentar basicamente no ser humano de que é a teoria. Como se poderia contribuir, doutro modo, à sua transformação? Ora, ao dizer-se que a transcendência é o sentido da 
Motricidade Humana, confere-se ao "corpo em acto" uma expressão profética, pois (repito-me) o que é não pode ser. Mas a extensão da transcendência não se limita aos aspectos físicos do ser humano. A sua constituição e diferença qualitativa, em relação à Educação Física, alarga a Motricidade Humana às dimensões intelectuais, morais, sociais e políticas da existência. Todavia, o conceito de "transcendência", ou superação, pode aplicar-se também à própria matéria. Ilya Prigogine enunciou o conceito de estrutura dissipativa, que associa as ideias de ordem e desperdício de energia e matéria, ou seja, de ordem e desordem, significando, com este conceito, a aptidão que um sistema aberto possui, para adquirir novas propriedades, em consequência de flutuações provenientes das suas interacções com o meio ambiente. A matéria revela-se, deste modo, capaz de auto-organizar-se. A entropia mostra-se não só produtora de desordem, mas de uma ordem com a coerência suficiente para dela emergirem novas propriedades dotadas de crescente autonomia, em relação ao meio ambiente. Segundo Prigogine, na irreversibilidade pode estar o segredo da organização biológica. Cito, a propósito, este autor, no seu livro O Nascimento do Tempo: "O livro de Schrodinger fez-me intuir, em 1945, que os fenómenos irreversíveis podiam ser a fonte da organização biológica e, a partir de então, esta ideia nunca mais me abandonou" (p. 27 da tradução portuguesa das Edições 70). Prigogine propõe-nos uma visão optimista da realidade, onde ao tempo-degradação da entropia sucede um tempo-criador que, à semelhança da durée bergsoniana, informa a evolução do universo. "Nos mais diversos ramos das ciências da natureza desenha-se, além disso, neste último quartel de século, o estertor definitivo do paradigma mecanicista, que vigorou na modernidade e tão grandes malefícios trouxe à ontologia, obrigando-a a um mais ou menos confesso dualismo substancial. Na verdade, como poderia comportar uma matéria, determinada por leis necessárias, a possibilidade e o acontecimento, em que se inscreve a aventura escalonante da vida?" (Mafalda de Faria Blanc, Introdução à Ontologia, Instituto Piaget, Lisboa, 1997, p. 125). Poderíamos ainda referir a geometria fractal, bem como a teoria do caos e a das catástrofes. Enfim, de uma forma ou de outra, a natureza surge como uma potência de organização e desenvolvimento, mais estruturada por processos e dinâmicas imparáveis do que por estados de ordem e de equilíbrio. Todas as criaturas, desde as estrelas aos macro e micro-organismos, encontram-se em permanente processo de reorganização. De facto, a própria matéria inerte é energia e não um conjunto de átomos rígidos, sujeitos a leis mecânicas de atracção e repulsão.

5. "Desde Descartes que pensamos contra a natureza, certos de que a nossa missão é dominá-la, conquistá-la" (Edgar Morin, O Paradigma Perdido, Publicações Europa-América, Lisboa, 1975, p. 15). Ora, em toda a acção, há que reconhecer "que as intersecções tempo-espaço se encontram envolvidas, em toda a existência social, de maneira essencial. A análise social terá de reconhecer (...) a existência de um sentido de différance que, mais do que duplo, tem um carácter triplo (...). A actividade social surge-nos sempre constituída, através de três momentos de diferença, entrecruzados temporalmente, paradigmaticamente (...) e espacialmente. Em todos estes sentidos, as práticas sociais são sempre actividades situadas, ou modos de actividade historicamente localizados" (Anthony Giddens, Dualidade da Estrutura - agência e estrura, op. cit., pp. 12 e 15). Em Heidegger, tudo o que existe é um ente, é devir, é tempo. Ora, o tempo donde nasceu a Educação Física não é o mesmo de hoje. Por isso, quando se fala em Educação Física, é preciso reflectir e provocar a reflexão, precisamente num tempo em que a reflexão é difícil e bem fácil a informação. E de uma informação, sem reflexão, a banalização pode ser o seu risco e o seu resultado. Discernir, procurar a significação e o sentido, agir intencionalmente na construção de uma sociedade mais justa e solidária parece mais árduo e menos cómodo do que estudar e promover as qualidades físicas, estender o império da técnica a toda a complexidade humana, esquecer a dimensão política de qualquer conduta intencional. A operacionalização da CMH depende da cultura, da competência e da liderança do professor, do técnico, do instrutor; da compreensão e receptividade do aluno, do atleta, do paciente; e das condições sociais, que os condicionam, ou melhor, da estrutura, do sistema e da estruturação. Não se aprende tão-só, através de regras e preceitos. A práxis é insubstituível: quem não pratica não sabe! Só que a práxis supõe uma formação, uma pedagogia. Assim, a CMH não põe em causa o progresso científico, em todas as suas formas, mas rejeita o Homem Máquina de Galileu e Descartes e Newton e Kant e 
da "mathesis universalis" e do positivismo e ainda dos liberais "laissez-faire" e laissez-passer", ou do monolitismo de qualquer ditadura. A CMH só existe na medida em que assume o ser humano, na integralidade das suas funções e das suas potencialidades. "Para Bakhtine, o maior teórico da literatura do século XX, como afirma Todorov (...), o objecto das ciências humanas não é um objecto, mas dois sujeitos. Esta tese implica que as ciências humanas surjam com um estatuto dialógico, em oposição ao estatuto monológico das ciências da natureza (...). Para Bakhtine, aliás, as ciências humanas tenderão a surgir como ramos específicos da própria semiótica, na medida em que o seu objecto genérico é o homem, mas não tudo o que diz respeito ao homem, antes o homem no que este possui de especificamente humano, isto é, o homem como produtor de textos" (in Eduardo Prado Coelho, Os Universos da Crítica, Edições 70, 1982, pp. 445446). Também na esteira de Bahktine, o estudioso da $\mathrm{CMH}$ (sem esquecer, no desporto, o professor e o treinador), porque se adentra ao nível das acções humanas, pode encontrar situações que não tenham exactidão científica, mas tenham valor cognitivo. A vontade de ciência pode deslegitimar outros tipos de saber? E tudo o que tenha valor cognitivo não cabe no âmbito de uma teoria científica? Anthony Giddens, nas suas Novas Regras do Método Sociológico (Zahar, Rio de Janeiro, 1978, p.144), acredita que num paradigma existem problemas compartilhados pelas ciências humanas e as ciências da natureza. Verdadeiramente, todos os paradigmas são mediados por outros.

6. Uma aula, ou um treino, à luz da $\mathrm{CMH}$, deve principiar, com esta pergunta, feita pelos que a compõem: "Que tipo de pessoa quero eu que nasça desta aula (ou deste treino)?’. E, depois, procurar-se-á unir e não separar os vários métodos pedagógicos (ou de treino) e a filosofia que os deve acompanhar, para que se passe do conhecimento daquilo que é ao conhecimento daquilo que deve ser. O ser humano não tem, unicamente, uma existência biológica (onde são visíveis também as complementaridades indivíduo/ grupo, indivíduo/espécie, indivíduo/sociedade, indivíduo/cultura), mas também uma existência, usando as palavras de Edgar Morin, antropossociológica, condicionada e construída pela sociedade, pela economia, pela cultura. Ora tudo isto deve estar presente, na educação, no desporto, na dança, na ergonomia e na reabilitação, na motricidade infantil, etc. "Hoje, a teoria dos sistemas substituiu a visão epistémica dos objectos pela dos sistemas, ou dos sistemas-objecto, entre os quais se encontra o sistema-objecto-sujeito-observador" (José Rozo Gauta, Sistémica y Pensamiento Complejo II. Sujeto, Educación, Trans-disciplinaridad, Biogénesis, Colombia, 2004, p. 133). De referir ainda que a noção de sistema evoluiu de uma simplicidade estática, encerrada e fechada em si mesma, para uma complexidade aberta, dinâmica, autopoiética, autorreferente e autorreflexiva, composta por elementos heterogéneos, que conformam e mantêm uma unidade sistémica, na qual as qualidades emergentes são maiores do que a soma das qualidades de cada um dos elementos. Estas ideias surgiram à margem da hiperespecialização que invadiu as várias disciplinas científicas, ao mesmo tempo que entraram de acentuar a necessidade para o conhecimento de sistemas-objectos, abertos, dinâmicos, autopoiéticos, auto-eco-organizadores e reflexivos - ao mesmo tempo que entraram de acentuar a necessidade, dizia, da inter, da trans, da multidisciplinaridade, enraizando (e não reduzindo) o físico-biológico no cultural e o cultural no físico-biológico. Com isto, não se violentam despoticamente as disciplinas, pois que elas mesmas se fortalecem no diálogo e convívio, com os outros ramos do saber. A operacionalização da CMH é praticar a unidade bio-antropo-sócio-cultural e política., dado que, em cada sistema, há elementos doutros níveis e sistemas. Cabe aos professores e aos técnicos trabalharem a complexidade, nos exercícos e nas acções que os seus alunos e atletas assumem. Não é ser sensato endurecer na atitude de conservação de métodos que a ciência e a filosofia consideram defuntos, irreversivel e definitivamente.

6. "De um ponto de vista conceptual, o poder encontra-se entre duas noções mais amplas: a de capacidade transformadora, por um lado, e a de dominação, por outro. O poder é relacional, mas só opera através da utilização da capacidade transformadora, tal como esta é gerada pelas estruturas de dominação" (Anthony Giddens, Dualidade da Estrutura - agència e estrutura, op. cit., p. 89). Oxalá o poder, seja ele qual for, com a vibratilidade típica do hermeneuta, se deite a pesquisar: se o que tradicionalmente se conhece como Educação Física tem, ou não, como objecto de teoria e de prática, a motricidade humana; se esta pode, ou não, organizar-se, logicamente, como uma ciência humana; e, se a motricidade humana é 
o "corpo em acto", os correspondentes "curricula" universitários não deverão rever-se, de modo a que se torne visível, no estudo e na pesquisa, um novo paradigma. De facto, é na busca de um novo paradigma que eu me situo - paradigma que não é objecto, mas sistema. A propósito, podemos chamar à colação o Edgar Morin de O Método - 1: "Os objectos dão o seu lugar aos sistemas; no lugar de essências e substâncias, organização; em vez de unidades simples e elementares, unidades complexas; em vez de agregados que formam corpo, sistemas de sistemas de sistemas" (p. 148). Daqui resulta que um sistema se constitui como uma rede de relações e de conexões, que podem realizar-se, quer em baixa, quer em alta complexidade (e quanto maior é a complexidade, maior é a incerteza). "Para realizar la descripción de las relaciones intrasistémicas, debemos tener en cuenta que cada elemento a su vez es un sistema con todas las características de sistema y cuyos elementos constituyentes no son elementos que pudiéramos llamar simples. Según Luhman, la diferencia entre sistema y entorno obliga a sustituir la diferencia entre el todo y las partes por una teoria de la diferenciación de sistemas. La diferenciación de sistemas es, simplemente, la repetición de la formación de sistemas dentro de los sistemas" (José Rozo Gauta, Sistémica y Pensamiento Complejo - paradigmas, sistemas, complejidad, Biogénesis, Colombia, 2003, p. 56). Assim, o que venho pretendendo organizar, de há quase trinta anos a esta parte, não é um novo objecto, mas uma nova unidade complexa ou sistema, a CMH. Também no desporto, na dança, na ergonomia, na reabilitação, etc., é preciso assumir em pleno a condição humana! Será de referir, por fim, que a Ciência da Motricidade Humana parece trazer contributos inestimáveis ao desporto de alta competição. E não só apontando a complexidade como a realidade primeira de todas os sistemas, mas porque a competição é impossível, se não se tem em conta a complexidade. Por outro lado, é preciso evitar o excesso de matematização como discurso da Verdade - esta, no ser humano é bem mais do que matemática (sem nunca excluir-se a matemática). Em livro, a que aludo sempre com grande respeito e admiração, da autoria de Luís Lourenço e Fernando Ilharco, Liderança - as lições de Mourinho, com prefácio do próprio José Mourinho (Booknomics, Lisboa, 2007) e livro, acrescento, que deverá estudar-se em todos os cursos universitários de desporto e em todos os cursos de treinadores $-o$ atual treinador do Manchester United não esconde que, para ele, "o treino faz parte do todo que é o jogo". E continua: "Julgo que nada é separado. Eu apresento a questão como uma dimensão de complexidade, porque na realidade, quando vamos para o terreno, tem de lá estar tudo" (p. 95). O começo instaurador do saber está na complexidade e, no caso da motricidade humana, uma complexidade em movimento intencional, procurando a transcendência. Mais uma despótica mentalinguagem? Tão-só a passagem de um saber analítico e disjuntivo para um saber novo, em que tudo é interdependente e complementar. É preciso educar a pessoa como um todo, para um desporto como um todo, para uma dança como um todo, para uma ergonomia como um todo, para uma reabilitação como um todo!

7. Porque tento exprimir um tempo de crise e de revolução científica, é uma "cultura intervalar"'(Fidelino de Figueiredo) o que emerge, sobre o mais, dos meus ensaios. De facto, o que eu posso apresentar é mais um pensamento que se ensaia continuamente do que um metassistema definitivamente realizado e composto. Sou pela reflexão ensaística, porque assim me sinto mais livre para apresentar, de forma argumentativa, uma teoria nova. O ensaio é uma forma peculiar de meditação que se alimenta do quotidiano, como em muitos textos de Montaigne. "É também característica do ensaio em geral a tentativa de apresentar sempre uma nova interpretação sobre um assunto banal ou transcendente, interpretação que confirma ou invalida anteriores tratamentos do tema. O que sobressai da relativa variedade temática é o apelo à reflexão, sem nunca ter preocupações de exaustividade, antes desnudando as próprias limitações ou incapacidades" (José Cândido de Oliveira Martins, Fidelino de Figueiredo e a crítica da teoria literária positivista, Instituto Piaget, Lisboa, 2007, p. 40). O ensaio, de facto, é uma constante da minha obra, dentro de um quadro de indagação filosófica - principal atitude do meu labor intelectual. A confirmar esta "simpatia" pelo ensaio, ocupei-me, aqui e agora, de perspectivar e antecipar o futuro da motricidade humana, longe de qualquer espírito sistemático, mas procurando uma nova intencionalidade, uma nova poética do possível, para o ser humano em movimento, que definitivamente se libertou do enclausuramento na auto-satisfação de um humanismo 
fechado em meia dúzia de saltos e corridas. A eficácia da $\mathrm{CMH}$ exige tanto a mudança dos exercícios, como a mudança das estruturas e das consciências. Mas nenhuma revolução se faz absolutamente só... para que a $\mathrm{CMH}$ se transforme em projecto histórico e político, tão anticapitalista, como anticolonialista! Termino, sublinhando que, para mim, a motricidade significa o movimento intencional da pessoa que, individual e coletivamente, visa superar e superar-se - física, intelectual, mortal e politicamente. Portanto, o profissional de Educação Física é, no meu entender, o especialista em motricidade humana, nas seguintes especialidades: Desporto, Dança, Ergonomia, Reabilitação, Motricidade Infantil, etc. E, porque se encontra no âmbito do humano, tendo em conta a Educação, a Saúde, o Lazer e o Trabalho. Tendo em conta o desenvolvimento humano. Boaventura de Sousa Santos, no seu livro Semear Outras Soluções (Edições Afrontamento, Porto, 2004), escreve: “cresce a influência e a importância da complexidade humana enquanto conceito transversal a diferentes disciplinas e áreas científicas" (p. 21). E portanto onde as artes e as humanidades têm também lugar relevante. A história das várias áreas do conhecimento é descontínua, atravessam-na revoluções científicas, mudanças de paradigmas, novas epistemes. Porque a revolução em que pensamos é tão epistemológica, como anti-capitalista, anti-colonialista e anti-sexista. A CMH é disto mesmo que fala, há mais de trinta anos. E termino com um abraço de muita admiração e simpatia ao Doutor Alfredo César Antunes.

Recebido em: 05.10.2017

Aceito em: 17.10.2017 